Submitted to Journal of Shape Memory and Superelasticity in revised form, July 2017

\title{
Investigation of the Dissolution - Reformation Cycle of the Passive Oxide Layer on NiTi Orthodontic Archwires
}

\author{
B. Uzer ${ }^{1}$, O. Birer ${ }^{2}$, D. Canadinc ${ }^{1,3, *}$ \\ ${ }^{1}$ Koç University, Advanced Materials Group (AMG), Department of Mechanical \\ Engineering, Sartyer, 34450 İstanbul, Turkey \\ ${ }^{2}$ Koç University, Department of Chemistry, Sariyer, 34450 İstanbul, Turkey \\ ${ }^{3}$ Koç University Surface Science and Technology Center (KUYTAM), Sariyer, 34450 \\ Istanbul, Turkey
}

\begin{abstract}
Dissolution-reformation cycle of the passive oxide layer on the nickel-titanium (NiTi) orthodontic archwires was investigated, which has recently been recognized as one of the key parameters dictating the biocompatibility of archwires. Specifically, commercially available NiTi orthodontic archwires were immersed in artificial saliva (AS) solutions of different $\mathrm{pH}$ values (2.3, 3.3 and 4.3) for four different immersion periods:1, 7, 14 and 30 days. Characterization of the virgin and tested samples revealed that the titanium oxide layer on the NiTi archwire surfaces exhibit a dissolution-reformation cycle within the first 14 days of the immersion period: the largest amount of $\mathrm{Ni}$ ion release occurred within the first week of immersion, while it significantly decreased during the reformation period of day 7 to day 14 . Furthermore, the oxide layer reformation was catalyzed on the grooves within the peaks and valleys due to relatively larger surface energy of these regions, which eventually decreased the surface roughness significantly within the reformation period. Overall, the current results clearly demonstrate that the analyses of dissolution-reformation cycle of the oxide layer in ${ }^{*}$ Corresponding author. Email: dcanadinc@ku.edu.tr; Phone: +90 212338 1891; Fax: +90 2123381548.
\end{abstract}


orthodontic archwires, surface roughness and ion release behavior constitute utmost importance in order to ensure both the highest degree of biocompatibility and an efficient medical treatment.

Keywords: NiTi; shape memory alloy; orthodontic archwire; dissolution-reformation cycle; oxide layer; biocompatibility; ion release.

\section{Introduction}

The Nickel-Titanium (NiTi) shape memory alloys (SMAs) have been employed in biomedical applications at an increasing rate within the last decades owing to their superior thermo-mechanical properties [1-10]. Specifically, the NiTi alloys can assume two distinctly different shapes by means of solid-to-solid phase transformation between austenitic and martensitic phases upon temperature change or loading [2,5,8-11], opening the venue for their utility in various dental, cardiovascular and orthopedic applications [2,7].

One of the well-known applications is the orthodontic archwire, which benefits from the pseudoelastic property of NiTi [2,5,7,9]: austenite-to-martensite phase transformation upon loading allows for attaining a state of constant stress for a relatively wide strain range $[2,7,9,11]$, which eliminates the need for frequent readjustments of the orthodontic arch wire to keep the stress at an optimum level for simultaneous tooth movement and periodontal tissue regeneration despite the changing strain on the wires [9]. Shape memory gloves which are used for the physiotherapy of partially atrophied muscles benefit from another important property, namely the two-way shape memory effect, such that the natural motion of a hand is mimicked with the wires placed in the regions over the fingers which contract and stretch by heating and cooling [5,12]. Consequently by the assistance of this glove the activity of the injured hand is maintained and the original hand motion would be promoted [12]. . 
Even though the NiTi alloy has been employed as a material of choice in various biomedical applications, biocompatibility related issues have constituted a significant concern and continue to come under focus in various studies $[1-10,13]$. In particular, when NiTi alloys are implanted in the body they are attacked by the aggressive ions of the body fluids, such as chlorides, hydrocarbonates or sulfates [14]. For instance, the high concentration of chloride ions in the saliva can cause pitting corrosion on the surface, which would further damage the material though the bulk and enhance the release of Ni ions in greater amounts [14-16]. As a result of corrosion assisted ion release the biocompatibility of the alloy, and thus, the success of the treatment could be significantly altered. In addition, stress corrosion cracking (SCC) constitutes another complication for the orthodontic treatments, such that when the archwires are loaded or archwire-bracket contact sites develop excessive stress along with the corrosivity of the saliva, the cracking of the archwires, and thereby the release of toxic $\mathrm{Ni}$ ions are enhanced $[17,18]$. When the amount of $\mathrm{Ni}$ ion release reaches a critical value of $0.12-0.5$ $\mathrm{mg} / \mathrm{L}$, serious toxic, carcinogenic and allergic effects may prevail, necessitating additional treatment $[2,8]$.

Recently, evidence has been forwarded demonstrating that the $\mathrm{Ni}$ ion release is dictated by several parameters, including the body location where the NiTi implant comes into contact with tissue, surface morphology of the implant material, and the passive oxide layer on the alloy surface $[8,9]$. Among these parameters, the passive oxide layer plays a critical role since it influences the Ni ion release, which in turn affects the biocompatibility of the implant $[2,6]$. Thermodynamically, formation of titanium oxide is favored over that of nickel oxide since titanium oxidizes more easily, and particularly forms titanium dioxide, which is stoichiometrically the most favorable oxide on the alloy surface [8,9]. Indeed, the surface of NiTi implants is usually covered with a protective oxide layer during the manufacturing process to prevent ion release [2]. However, this protective layer may not constitute a 
thorough prevention against ion release since it can possess cracks or defects which can be acquired during manufacturing or service $[2,4]$.

Surface roughness of the archwires has also been reported to be an important parameter since it affects the biocompatibility of the material, friction between the archwire and the brackets, and the efficient sliding mechanism, all of which dictate the success of the orthodontic treatment $[17,19,20]$. For instance, the archwire-bracket contact sites possessing greater surface roughness than the remaining parts of the archwire, which are not in direct contact with the brackets, significantly increase the friction force and hinder an efficient archguided tooth movement $[17,19]$. In this case, application of greater forces on the wires becomes necessary for the remainder of the treatment, yet this can result in the undesirable SCC leading to significant Ni ion release [17].

Growth of the passive oxide layer during service, and its correlation with $\mathrm{Ni}$ ion release rate and the biocompatibility of NiTi implants have been addressed in various immersion studies $[2,8,10]$. An excess amount of $\mathrm{Ni}$ release was reported on the second day of an immersion experiment as opposed to significantly smaller amounts in the later stages of the experiment [8]. Particularly, an oxide layer forms on the outer layer mostly with Ti depleted $\mathrm{Ni}$, and the initially dissolved $\mathrm{Ni}$ ions start to form compounds with the $\mathrm{Ti}$ ions beneath the oxide layer during the later stages of the immersion, which results in the decrease of the $\mathrm{Ni}$ ion concentration in the culture media [8]

The passive oxide layer may not grow monotonously in an immersion experiment. Depending on the $\mathrm{pH}$ of the environment, a dissolution-reformation cycle may take place, dictating the instantaneous thickness of the oxide layer, $\mathrm{Ni}$ release rate and the biocompatibility of the implant material $[2,21]$. When the oxide layer dissolves faster than it reforms, the rate of ion release increases owing to the weaker protection provided by the 
thinner oxide layer [2]. On the other hand, a reformation faster than the dissolution yields a thicker oxide layer and a nickel rich oxide-metal interface [4,13]. A thicker oxide layer exhibits a more brittle behavior as compared to a thin oxide layer, and thus, promotes formation of defects or cracks, both of which can eventually result in more severe $\mathrm{Ni}$ ion release $[4,13]$. Therefore, the oxide layer on the implant material needs to meet important criteria, such as minimum toxic $\mathrm{Ni}$ ion release and lowest corrosion rate to achieve a successful treatment. Consequently, the dissolution-reformation cycle constitutes one of the major parameters influencing the biocompatibility of the implant, and lack of knowledge about this cyclic alteration warrants further investigation.

The dissolution-reformation cycle of orthodontic applications depends strongly on the $\mathrm{pH}$ of the saliva $[18,22,23]$. Saliva with acidic $\mathrm{pH}$ values $(\mathrm{pH}<7)$ is more corrosive and can attack on the archwire surface resulting in $\mathrm{Ni}$ ion release from the archwire into the intra oral cavity. Natural saliva exhibits varying $\mathrm{pH}$ values depending on the changing saliva flow rate, which is affected by age, genetic heritage, dietary habits, exercise and medication [24-27]. While the normal $\mathrm{pH}$ values are between 6.2-7.4, values as low as 2.0-2.5 are also possible [26-28]. The current study was undertaken with the motivation of understanding the dissolution-reformation cycle of the oxide layer on NiTi archwires in detail, and establishing its relationship with the $\mathrm{Ni}$ ion release from the alloy. For this purpose, static immersion experiments were carried out, where NiTi orthodontic archwires were immersed in artificial saliva (AS) solutions with different $\mathrm{pH}$ values simulating various possible intra oral environments. Dissolution-reformation cycle of the oxide layer was investigated on the archwires immersed in AS solution with a $2.3 \mathrm{pH}$ value for 1, 7, 14 and 30 days since this particular AS solution represents the most corrosive intra oral environment. The current findings demonstrate that the protective titanium oxide layer on the NiTi archwires immersed in the AS with a $\mathrm{pH}$ of 2.3 undergo a dissolution-resolution cycle that complies well with the 
ion release into the solution within the first 14 days of the immersion period. Furthermore, the current results also point at the necessity of eliminating any alterations to the surface roughness and topography of the archwires during manufacturing in order to ensure the biocompatibility of archwires and provide an efficient treatment for the patients.

\section{Experimental Details}

Dissolution-reformation cycle of the passive oxide layer on the NiTi samples was investigated by utilizing static immersion experiments. The NiTi specimens used in this study were orthodontic archwires ${ }^{\dagger}$ having a chemical composition of 54.5-57 wt. \% $\mathrm{Ni}$ and an austenite finish temperature within the range of $20-40{ }^{\circ} \mathrm{C}$ (as specified by the manufacturer). Prior to the immersion, the samples were cleaned in an ultrasound bath with ethanol in order to remove dirt, dust or metallic powder that may have been left on the surface. The native oxide layer on the NiTi sample surfaces was not removed since the implants employed in human body also possess this protective layer. For the immersion experiments, intraoral environment was simulated by artificial saliva (AS) which was prepared with the chemicals listed in Table 1. These chemicals were mixed in a beaker with deionized water and the solution was heated up to and kept constant at body temperature $\left(37^{\circ} \mathrm{C}\right)$ by a hot plate stirrer. These solutions were prepared with three different $\mathrm{pH}$ values, namely $2.3,3.3$ and 4.3 , with the intention of better understanding of the corrosive effect of the different acidic $\mathrm{pH}$ values on the NiTi archwires. The acidity of the solutions was adjusted by adding $1 \mathrm{M} \mathrm{HCl}$ slowly. Dissolution-reformation cycle was investigated on the orthodontic archwires immersed in the solution with the $\mathrm{pH}$ value of 2.3 for $1,7,14$ and 30 days of immersion periods which will be referred to as D1, D7, D14 and D30 throughout the text, respectively. A different set of

\footnotetext{
${ }^{\dagger} 3 \mathrm{M}$ Unitek Nitinol heat-activated archwires with $0.36 \mathrm{~mm}$ diameter were used in the experiments.
} 
experiments was carried out by the immersion of NiTi archwires in the AS solutions with the $\mathrm{pH}$ values of $2.3,3.3$ and 4.3 for 30 days long in order to evaluate the overall oxide layer thickness dependence on the acidity of the intraoral environment. Each archwire sample was immersed in a certain amount of AS solution which meets a predefined solution volume per surface area ratio of $20 \mathrm{~mL} / \mathrm{cm}^{2}$ [30]. Throughout the immersion experiments, samples were kept in separate sealed tubes and placed into an electronically controlled water bath which sustained the body temperature.

The surface topography of each sample was monitored with field emission scanning electron microscopy (FESEM, Ultra Plus, Zeiss, Germany) both prior to and following immersion experiments. The samples were investigated with $5 \mathrm{kV}$ of primary electron energy to avoid charging and surface damage. The samples were not coated with a thin conducting layer. The images were taken with two different detectors simultaneously and displayed on split screen mode, such that one part of the image was recorded by the in-lens detector which detects primarily SE1 type secondary electrons, enhancing the material contrast. The other part of the image was recorded by the Everhart-Thornley secondary electron detector, which detects SE1+SE2+SE3 type secondary electrons and is sensitive to surface morphology.

The surface chemical composition and depth profiles of samples were analyzed by Xray photoelectron spectroscopy (Thermo Scientific K-alpha XPS). In order to achieve a statistical consistency, XPS results were collected from 3 different points on each sample. The XPS system had a monochromatic aluminum target micro-focus X-ray source $(1486.7 \mathrm{eV})$. The samples were taped to the edge of the sample holder so that $10 \mathrm{~mm}$ segments were suspended freely in air. The analyses were carried out with a 300 micrometer X-ray spot size on the suspended regions of the wires to avoid superfluous substrate signals. The spectra were recorded in the so called "snap shot" mode where the pass energy was $150 \mathrm{eV}$ and the 128 pixel detector saw the corresponding energy spread of electrons. The spectra were later 
energy deconvoluted with the point spread function to reach an effective energy resolution equivalent of $50 \mathrm{eV}$ pass energy, i.e. $0.5 \mathrm{eV}$. A flood gun was used for charge compensation. The base pressure of $1 \times 10^{-9}$ mbar rose to $1 \times 10^{-7}$ mbar under operation. The depth profiling was carried out with $2 \mathrm{keVAr}^{+}$beam. The spectra were referenced for the $\mathrm{C}$ 1s signal at 285.0 $\mathrm{eV}$ and quantified with Avantage v5 software by Thermo Fischer Scientific. The carbon and oxygen regions were fitted with 40/60 Gaussian/Lorentzian peaks. The high resolution titanium spectra, on the other hand, was analyzed with principal component analysis (PCA) due to the complex nature of oxide/interface/bulk metal regions and the multitude of substoichiometric species. The nickel $2 \mathrm{p}$ signal $\left(\mathrm{Ni}^{0}\right)$ was integrated and quantified using the Scofield factor. An estimated $0.14 \mathrm{~nm} / \mathrm{s}$ etch rate was used to convert etch time to depth values.

Released $\mathrm{Ni}$ and $\mathrm{Ti}$ ions from the archwires into immersion fluids were detected with ICP-MS equipped with octopole reaction system helium collision cell for spectral interference removal, rather than ICP-OES, considering the $\mu \mathrm{g} / \mathrm{L}(\mathrm{ppb})$ level ion detection capability of the former. The ICP-MS was operated with MicroMist glass concentric nebulizer, quartz Scotttype spray chamber and Ni sampler/skimmer cones. Daily instrumental optimizations were performed using $1 \mu \mathrm{g} / \mathrm{L}$ tuning solution for the short-term stability of the instrument. The corresponding instrument settings and parameters are provided in Table 2.

Surface roughness of each archwire sample was evaluated by atomic force microscopy (AFM). Considering the irregularities on the archwire surface due to manufacturing processes AFM images were obtained from the uniform regions which were detected by scanning the archwires' surfaces thoroughly. This technique eliminated the deviations between each measurement and provided more reliable surface roughness results. The AFM images were captured in the tapping mode in air utilizing an antimony (n) doped silicon cantilever with a rotated tip of a radius $8 \mathrm{~nm}$ and resonance frequency of $75 \mathrm{kHz}$. The linear scanning rate was 
set as $1 \mathrm{~Hz}\left(1\right.$ line/s) and image size was $30 \times 30 \mu \mathrm{m}^{2}$. The measurements were repeated at least 5 times for the sake of reliability and statistical consistency, and the surface roughness $\left(R_{a}\right)$ values were determined based on their average.

\section{Results and Discussion}

Biocompatible NiTi orthodontic archwires were subjected to static immersion experiments for different durations in AS solutions featuring different $\mathrm{pH}$ values, and the ICPMS, AFM, SEM and XPS analyses demonstrated prominent differences between the samples immersed in different solutions. For instance, $\mathrm{Ni}$ and $\mathrm{Ti}$ ion releases from the archwires into the AS solutions with $2.3 \mathrm{pH}$ were significantly more as compared to $\mathrm{Ni}$ and $\mathrm{Ti}$ ions released into other solutions (Figure 1). When the $\mathrm{pH}$ of the solution increased from 2.3 to 3.3 the $\mathrm{Ni}$ and $\mathrm{Ti}$ ion release decreased about 16 fold. However, further increase of the AS solution $\mathrm{pH}$ to 4.3 led to only a very slight decrease in ion release (Figure 1). The prominent change in the ion release behavior when the $\mathrm{pH}$ values increased from 2.3 to 3.3 shows that the AS solution's $\mathrm{pH}$ in this range influences ion release behavior drastically and makes the archwires more prone to corrosion.

The significant effect of the solution $\mathrm{pH}$ on the ion release was previously analyzed in scientific studies, and the adverse effect of the acidic $\mathrm{pH}$ on biocompatibility was pointed out $[23,31,32]$. In particular, analyses of archwires immersed in solutions with a wide range of $\mathrm{pH}$ values showed that the amount of metal ion release was almost undetectable in the solutions with $\mathrm{pH} \geq 3.75$, which implies that significant ion release takes place especially in the solutions with the $\mathrm{pH}<3.75$ [31]. In the current study, the most significant decrease of the ion release was observed in the solutions with the $\mathrm{pH}<3.3$, however; detectable ion release was prominent when $\mathrm{pH} \geq 3.3$, as well (Figure 1). The current results demonstrate that the 
orthodontic archwires are significantly affected by the solution $\mathrm{pH}$ and metal ions release is the greatest in the most acidic environment. However, it should also be noted that Ni ion released into all of the utilized solutions stayed far below the critical Ni level (0.12-0.5 ppm) that may cause allergic reactions [17]. The released Ti ions detected by ICP-MS, on the other hand, do not pose any threat because they are not cytotoxic as $\mathrm{Ni}$ ions, however; the $\mathrm{Ti}$ ion presence in the solution implies the dissolution of the protective $\mathrm{Ti}$ oxide layer, which could eventually lead to enhanced Ni ion release [31]. This argument can be supported by the SEM analysis of the tested samples: the SEM images of these archwires which were immersed in the AS solutions with $\mathrm{pH}$ values of 2.3, 3.3 and 4.3 for 30 days are presented in Figure 2. The surfaces of the archwires immersed in 3.3 and $4.3 \mathrm{pH}$ solutions look rather smooth when compared with the that of the one immersed in $2.3 \mathrm{pH}$ AS, which stems from the more aggressive environment imposed by the lower $\mathrm{pH}$. Specifically, non-uniform dissolution of the protective oxide layer due to the greater acidity of the solution leads to a lower corrosion resistance [3], which, in turn, enhances Ti ion release (Figure 1), deteriorates the surface and alters the topography (Figure 2(a)).

In order to understand the effect of dissolution-reformation cycle of the titanium oxide layer on the ion release behavior, a different set of experiments were performed for four different time periods (1, 7, 14 and 30 days - referred to as D1, D7, D14 and D30, respectively) in the AS solution with a $\mathrm{pH}$ of 2.3. The cumulative amounts of $\mathrm{Ni}$ and $\mathrm{Ti}$ ions released from the archwires into this solution were also measured and presented in Figure 3. In order to analyze the net ion release within each immersion interval the ion release concentration of the previous time period was subtracted from the following one. For instance, in order to find the net ion release within the immersion interval of D7-D14, the total ion release concentration of D7 was subtracted from the total value of D14. These net ion release values are plotted in Figure 4, which were also presented in Table 4 in a normalized 
fashion (by the number of days within each interval) for the sake of obtaining the ion release rate within each immersion interval This table reveals an interesting result, such that the ion release rate of $\mathrm{Ti}$ ion from $\mathrm{D} 0$ to $\mathrm{D} 1$ shows greater value than the $\mathrm{Ni}$ ion release rate, which might stem from the initial dissolution of protective oxide layer. The Ti ion release rate drops between D1 and D7 while that of the Ni ion increases slightly possiblly due to weaker protection against corrosion. For both $\mathrm{Ti}$ and $\mathrm{Ni}$ the release rate drops significantly after D7. Following D14, the ion release rate was lower compared to the release rate of the immersion for the interval of D0 to D7. This results show that the orthodontic archwires were more prone to corrosion during the immersion period of D0-D7, and thus, the major ion release occurred within the first 7 days of the immersion, which agrees well with the literature [32].

In order to comprehend the oxide layer dissolution-reformation cycle, XPS analysis was carried out on the as-is, D1, D7, D14 and D30 samples (D30 immersed in pH 2.3, 3.3 and 4.3), and the corresponding depth profile data is presented in Figure 5. The Ti region XPS spectra were processed using principal component analysis to identify the oxide, intermediate sub-oxide and the metallic moieties. The quantification of these moieties was performed with the Scofield factors and plotted as atomic percentages as a function of etching time. The $\mathrm{x}-$ axis of this plot can be converted to a depth axis, however a reliable etch rate is difficult to assign to different species. Nevertheless, an estimated etch rate of $0.14 \mathrm{~nm} / \mathrm{s}$ can be assigned for $\mathrm{Ta}_{2} \mathrm{O}_{5}$ etching under these conditions. The plot shows the relative amounts of the oxide, intermediate and metallic titanium species on the surface of the species. The ion energy of $500 \mathrm{~V}$ was specifically chosen not to reduce the titanium +4 species during bombardment and not to yield superfluous signal. One can use the following plot to compare the oxide thicknesses of the samples using either the maximum amount of the intermediate species or the rising edge of the metallic titanium species. We have chosen the initial signal obtained from the metallic titanium which was achieved by the bombardment of the archwire surface 
with the argon ions and removal of the oxide layer covering the archwire surface. In order to speculate about the oxide layer thicknesses of the archwires the etch time (depth axis) corresponding to the time of the first metallic Ti signal acquisition was multiplied by the etch rate $(0.14 \mathrm{~nm} / \mathrm{s})$. The oxide layer thickness of the days $1,7,14$ and 30 was approximately evaluated as 5.64, 1.64, 4.36 and $7.1 \mathrm{~nm}$. The depth profile data of the as-is archwire showed a significantly thinner oxide layer than all of the immersed archwires. But the sample immersed in AS even for 1 day exhibited a thicker oxide layer than the as-is one. This result can affirm that the oxide layer formation due to AS solution-archwire interaction started right after the immersion [8]. After D1, oxide layer dissolution was observed on the sample immersed in AS for 7 days. After D7, it started reforming again until D14, and thereafter it kept increasing until D30 in a more stable manner. It is noteworthy that the oxide layer dissolution-reformation cycle follows a trend in the first 14 days of immersion. Accordingly, there might be a decrease in the oxide layer thickness during D14-D21, followed by an increase during D21-D30. Since D21 was not included in the current experiments, this aspect was left for future work.

The XPS spectra recorded during the depth profiling of the sample immersed in AS with the $\mathrm{pH}$ of 2.3 for 30 days is presented in Figure 6 . The y-scales of the spectra are kept the same for each element in 3 panels for direct comparison. The labels on the left indicate the extent of argon ion bombardment with $\mathrm{t}=0$ corresponds to the pristine sample surface. The top surface was dominated by $\mathrm{Ti}$ oxide with the $\mathrm{Ti} 2 \mathrm{p}_{3 / 2}$ signal located at $458.5 \mathrm{eV}$ for the $\mathrm{Ti}^{4+}$ species. The O1s region was deconvoluted to 3 peaks, which corresponds to the metal oxide $\left(\mathrm{TiO}_{2}, 530 \mathrm{eV}\right)$, sub-oxide $\left(\mathrm{TiO}_{\mathrm{x}<2}, 531.5 \mathrm{eV}\right)$ and surface adsorbed water $(533 \mathrm{eV})$. The nickel $2 \mathrm{p}_{3 / 2}$ region had a very weak signal for the metallic nickel indicating the inertness of $\mathrm{Ni}$ and the thickness of the Ti oxide on the surface. As the surface etching proceeded $(t=50 \mathrm{~s})$, the carbon signal started to decrease, and signals from the oxide layer increased accordingly. 
The Ti region shows the sub-oxide peaks, as well as weak metallic moiety, while the oxygen region peaks show slight enhancement due to the removal of the carbon contamination. The Ni signal increased without a change in binding energy, i.e. still in metallic phase. Towards the end of the etching study ( $\mathrm{t}=400 \mathrm{~s}$ ), the carbon species still persisted as a weak signal, which indicates that the carbon was actually embedded into material during production, surface treatment or due to carbon deposition throughout the immersion period in AS solution, which contained urea. The metallic Ni and metallic Ti signals dominated the spectra, while some oxygen species still remained. A possible reason for tenacious oxygen presence is that the surface was not smooth and may have several nano and micro cracks. Therefore, the oxide presence on the surface could be detected even for extended periods of vigorous ion bombardment.

In addition to the dissolution-reformation cycle, the oxide layer thickness has also a critical effect on the ion release behavior from the archwire into the AS solution, such that when the oxide layer dissolves the total amount of ions in the AS solution increases [2]. This can be verified by examining the ICP-MS data obtained from the archwires immersed in the AS solution for different immersion periods (Figure 4). For instance the significant decrease observed in the oxide layer thickness from D1 to D7 is noteworthy because dissolution of the oxide layer leads to the release of notable amount of $\mathrm{Ti}$ ions from the oxide and $\mathrm{Ni}$ ions either from the substrate or Ni-rich sublayers [4]. After D7, the Ti ions released in the AS solution takes role in the reformation of the oxide layer in D14, which explains the decrease of the amount of Ti ions in the AS. During this reformation, Ni ions move towards the oxide metal interface where they can join the bulk, form different compounds underneath or within the $\mathrm{TiO}_{2}$ layer $[2,13,33]$. In particular, the ICP-MS results show that on D1 the total amount of Ti ion is more than that of $\mathrm{Ni}$ ions. This can be due to the initial release of the Ti ions from the initial protective oxide layer on the outer surface of the archwires. Therefore, to attack the Ni- 
rich layers or substrate, and lead to $\mathrm{Ni}$ ion release, aggressive chloride ions need to move through the oxide layer and reach underneath. However, from D1 to D7, the total Ni ion release exceeded the $\mathrm{Ti}$ ion release, which can be associated with the stability of the Ti oxide layer [34].

The surface roughness of the archwires also plays a critical role on their biocompatibility, and the efficiency of the medical treatment [17]. Specifically, any irregularities on the archwire surface create high energy regions, which become more prone to corrosion, and thus, enhance ion release. In order to eliminate this unfavorable ion release, surface uniformity and quality need to be ensured $[4,35,36]$. However, SEM analysis of the as-is archwires demonstrated that irregularities and/or imperfections were present on the surfaces, increasing the surface roughness and potentially enhancing the corrosion assisted ion release (an example is shown in Figure 7). Thus, for an efficient orthodontic treatment and for the sake of biocompatibility, maintaining high quality during the manufacturing of the archwires is of utmost importance.

Surface roughnesses $\left(\mathrm{R}_{\mathrm{a}}\right)$ of the archwires which were immersed for $1,7,14$ and 30 days in the AS solution with $2.3 \mathrm{pH}$, and those immersed in the AS solutions with the $\mathrm{pH}$ values of 3.3 and 4.3 for 30 days were evaluated with AFM, and the corresponding results are listed in Table 3. Accordingly, the surface roughness increased slightly when the archwire was immersed in the AS solution and subjected to corrosion even only for 1 day which might stem from a weaker protection against corrosion because of a thinner oxide layer. Between D1 and D7 $R_{a}$ continued to increase, which verifies the corrosive effect of the AS between D1 and D7. This result is compatible with the oxide layer thickness and the ion release measurements, such that in this immersion period (D1-D7) archwire surface was attacked by $\mathrm{Cl}$ ions, which eventually leads to oxide layer dissolution, enhances ion release and increases the surface roughness. However, the roughness analysis of the archwire immersed for 14 days revealed a 
drastic decrease in roughness from D7 to D14. This result also affirms the findings of the oxide layer and ion release measurements, such that $\mathrm{Ti}$ ions form the $\mathrm{Ti}$ oxide with the dissolved oxygen in the AS, and this reformed oxide layer deposits specifically over the grooves within the peaks and valleys of the archwire which possess relatively larger surface energy, making the reformation easier, and eventually resulting in a smoother archwire surface (Figure 8) [17]. Specifically, the deposition of the corrosion products on cracks, pitting sites or surface defects is favored because of their greater surface energy $[2,14,17]$. Eventually, oxide layer formation on the rough regions leads to the decrease of surface roughness, meanwhile the ion release is hindered owing to the thicker oxide layer. From D14 to D30 a slight increase in the roughness was observed, implying that the oxide layer formation had reached to a more stable state.

\section{Conclusions}

The experimental work presented in this paper showed that the protective titanium oxide layer on the NiTi orthodontic archwires studied in the current work undergoes dissolution and reformation cycle within the first 14 days of the immersion period. The archwires immersed in artificial saliva (AS) solution for different time periods (1, 7, 14 and 30 days) and $\mathrm{pH}$ values $(2.3,3.3$ and 4.3$)$ exhibited the greatest amount of $\mathrm{Ni}$ ion release within the first 7 days of the immersion, i.e. the dissolution of the oxide layer; whereas the net ion release decreased significantly along with the reformation of the oxide layer within days 7-14. The change of the surface roughness was observed to stand in good agreement with the dissolutionreformation cycle, such that the reformation of the oxide layer within the peaks and valleys of the archwire surface resulted in a significant decrease of the surface roughness. Additional immersion experiments carried out in the AS solutions with different $\mathrm{pH}$ values clearly presented the aggressive effect of the most acidic environment $(\mathrm{pH}=2.3)$ with the deteriorated 
surface and enhanced ion release. In addition, the surface defects due to the manufacturing processes were observed to enhance corrosion. Overall, the current findings clearly demonstrated that the oxide layer dissolution-reformation cycle needs to be analyzed thoroughly along with surface roughness and ion release behavior in order to ensure the highest biocompatibility standards for NiTi orthodontic archwires.

\section{Acknowledgements}

D. Canadinc and O. Birer acknowledge the financial support by the Turkish Academy of Sciences (TÜBA) within the Outstanding Young Scientist Program (GEBİP). B. Uzer acknowledges the financial support by the Scientific and Technological Research Council of Turkey (TÜBİTAK) within the National Graduate Student Fellowship Program 2211. The SEM, EDX, AFM and XPS analyses were carried out at Koç University Surface Science and Technology Center (KUYTAM).

\section{References}

[1] Tian, H., Schryvers, D., Liu, D., Jiang, Q., Van Humbeeck, J.: Stability of Ni in nitinol oxide surfaces. Acta Biomaterialia. 7(2), 892-899 (2011)

[2] Toker, S.M., Canadinc, D., Maier, H.J., Birer, O.: Evaluation of passive oxide layer formation-biocompatibility relationship in NiTi shape memory alloys: Geometry and body location dependency. Materials Science \& Engineering C. 36, 118-29 (2014)

[3] Trepanier, C., Venugopalan, R., Pelton, A.R.: Corrosion resistance and biocompatibility of passivated NiTi, Springer Berlin Heidelberg, (2000) 
[4] Zhu, L., Trépanier, C., Pelton, A.R, Fino, J.: Oxidation of Nitinol and Its Effect on Corrosion Resistance, 156-161 (2003)

[5] Machado, L.G, Savi, M.A.: Medical applications of shape memory alloys. Brazilian Journal of Medical and Biological Research. 36(6) 683-691 (2003)

[6] Shabalovskaya, S.A., Rondelli, G.C., Undisz, A.L., Anderegg, J.W., Burleigh, T.D., Rettenmayr, M.E.: The electrochemical characteristics of native Nitinol surfaces. Biomaterials. 30(22), 3662-3671(2009)

[7] Duerig, T.: The Use of Superelasticity in Modern Medicine. MRS Bulletin. 27(02), $101-104(2002)$

[8] Ryhänen, J., Niemi, E.U.O.O., Serlo, W., Niemelä, E., Sandvik, P., Pernu, H. and Salo, T.: Biocompatibility of nickel-titanium shape memory metal and its corrosion behavior in human cell cultures. Journal of Biomedical Materials Research. 35(4), 451457(1997)

[9] Toker, S.M, Canadinc, D.: Evaluation of Biocompatibility of NiTi Dental Wires: A Comparison of Laboratory Experiments and Clinical Conditions. Materials Science and Engineering: C. 40, 142-147 (2014)

[10] Wever, D.J., Veldhuizen, A.G., Sanders, M.M., Schakenraad, J.M., Van Horn, J.R.: Cytotoxic, allergic and genotoxic activity of a nickel-titanium alloy. Biomaterials. 18(16), 1115-1120 (1997)

[11] Otsuka, K., Ren, X.: Recent developments in the research of shape memory alloys. Intermetallics. 7(5), 511-528 (1999)

[12] Petrini, L., Migliavacca, F.: Biomedical Applications of Shape Memory Alloys. Journal 
of Metallurgy. (2011)

[13] Shabalovskaya, S.A., Tian, H., Anderegg, J.W., Schryvers, D.U., Carroll, W.U. and Van Humbeeck, J.: The influence of surface oxides on the distribution and release of nickel from Nitinol wires. Biomaterials. 30(4), 468-477 (2009)

[14] Hu, T., Chu, C., Xin, Y., Wu, S., Yeung, K.W. and Chu, P.K.: Corrosion products and mechanism on NiTi shape memory alloy in physiological environment. Journal of Materials Research. 25, 350-358 (2010)

[15] Li, X., Wang, J., Han, E.H., Ke, W.: Influence of fluoride and chloride on corrosion behavior of NiTi orthodontic wires. Acta Biomaterialia. 3(5), 807-815 (2007)

[16] Ma, F.Y.: Corrosive Effects of Chlorides on Metals. INTECH Open Access Publisher (2012)

[17] Uzer, B., Gumus, B., Toker, S.M., Sahbazoglu, D., Saher, D., Yildirim, C., PolatAltintas, S., Canadinc, D.: A Critical Approach to the Biocompatibility Testing of Niti Orthodontic Archwires. International Journal of Metallurgy and Metal Physics. 1, 1-7 (2016)

[18] Wang, J., Li, N., Rao, G., Han, E.H. and Ke, W.: Stress corrosion cracking of NiTi in artificial saliva. Dental Materials. 23(2) 133-137 (2007)

[19] Castro, R.M., Smith Neto, P., Horta, M.C.R., Pithon, M.M., Oliveira, D.D.: Comparison of static friction with self-ligating, modified slot design and conventional brackets. Journal of Applied Oral Science. 21(4), 314-319 (2013)

[20] Bourauel, C., Fries, T., Drescher, D., Plietsch, R.: Surface roughness of orthodontic wires via atomic force microscopy, laser specular reflectance, and profilometry. 
European Journal of Orthodontics. 20(1), 79-92 (1998)

[21] Hanawa, T.: In vivo metallic biomaterials and surface modification, Materials Science and Engineering A. 267(2), 260-266 (1999)

[22] Kim, H., Johnson, J.W.: Corrosion of stainless steel, nickel-titanium, coated nickeltitanium, and titanium orthodontic wires. Angle Orthodontist. 69(1) 39-44 (1999)

[23] Huang, H.H.: Surface characterizations and corrosion resistance of nickel-titanium orthodontic archwires in artificial saliva of various degrees of acidity. Journal of Biomedical Materials Research - Part A. 74(4) 629-639 (2005)

[24] Schipper, R.G., Silletti, E. Vingerhoeds, M.H.: Saliva as research material: biochemical, physicochemical and practical aspects. Archives of Oral Biology. 52(2), $1114-1135(2007)$

[25] Dodds, M.W., Johnson, D.A., Yeh, C.K.: Health benefits of saliva: a review. Journal of Dentistry. 33(3), 223-233 (2005)

[26] Diaz-Arnold, A.M. and Marek, C.A.: The impact of saliva on patient care: A literature review. Journal of Prosthetic Dentistry. 88(3), 337-343 (2002)

[27] Chicharro, J.L., Lucía, A., Pérez, M., Vaquero, A.F. and Ureña, R.: Saliva composition and exercise. Sports Medicine. 26(1) 17-27 (1998)

[28] Chiappin, S., Antonelli, G., Gatti, R. and Elio, F.: Saliva specimen: A new laboratory tool for diagnostic and basic investigation. Clinica Chimica Acta. 383(1) 30-40 (2007)

[29] Onal, O., Gumus, B., Aksoy, B., Gerstein, G., Alaca, B.E., Maier, H.J., Canadinc, D.: Micro-scale cyclic bending response of NiTi shape memory ally. Mater. Trans. 57(3) $472-475(2016)$ 
[30] Corbett, R.A.: Corrosion Tests and Standards: Application and Interpretation-Second Edition (2005)

[31] Huang, H.H., Chiu, Y.H., Lee, T.H., Wu, S.C., Yang, H.W., Su, K.H. and Hsu, C.C.: Ion release from NiTi orthodontic wires in artificial saliva with various acidities, Biomaterials. 24(20), 3585-3592 (2003)

[32] Kuhta, M., Pavlin, D., Slaj, M., Varga, S., Lapter-Varga, M. and Slaj, M.: Type of archwire and level of acidity: Effects on the release of metal ions from orthodontic appliances. Angle Orthodontist. 79(1), 102-110 (2009)

[33] Firstov, G.S., Vitchev, R.G., Kumar, H., Blanpain, B. and Van Humbeeck, J.: Surface oxidation of NiTi shape memory alloy, 23(24), 4863-4871 (2002)

[34] Ryhänen, J.: Biocompatibility Evaluation of Nickel- Titanium Shape Memory Metal Alloy. Springer (1999)

[35] Huang, H.H.: Corrosion resistance of stressed NiTi and stainless steel orthodontic wires in acid artificial saliva. Journal of Biomedical Materials Research Part A. 66(4), 829-839 (2003)

[36] Trepanier, C., Tabrizian, M., Yahia, L.H., Bilodeau, L. and Piron, D.L.: Effect of modification of oxide layer on NiTi stent corrosion resistance. Journal of Biomedical Materials Research. 43(4), 433-440 (1998) 
Table 1. Chemical content of the artificial saliva used in immersion experiments.

\begin{tabular}{cc}
\hline Ingredients & Amount of Ingredients $(\boldsymbol{g} / \mathbf{l})$ \\
\hline $\mathrm{NaCl}$ & 0.4 \\
$\mathrm{KCl}$ & 0.4 \\
$\mathrm{CaCl}_{2} \cdot 2 \mathrm{H}_{2} \mathrm{O}$ & 0.906 \\
$\mathrm{NaH}_{2} \mathrm{PO}_{4} \cdot 2 \mathrm{H}_{2} \mathrm{O}$ & 0.690 \\
$\mathrm{Na}_{2} \mathrm{~S} \cdot 9 \mathrm{H}_{2} \mathrm{O}$ & 0.005 \\
$\mathrm{Urea}$ & 1 \\
\hline
\end{tabular}

Table 2. ICP-MS operating parameters.

\begin{tabular}{ll|ll}
\hline Number of points per peak & 3 & Plasma gas flow (Argon) & $15 \mathrm{~L} / \mathrm{min}$ \\
Replicates & 5 & Helium gas flow (Collision cell) & $4.3 \mathrm{ml} / \mathrm{min}$ \\
Sweeps/replicate & 100 & Carrier gas flow (Argon) & $1 \mathrm{~L} / \mathrm{min}$ \\
Integration time per mass & $0.12 \mathrm{~s}$ & Plasma Forward Power & $1550 \mathrm{~W}$ \\
\hline
\end{tabular}

Table 3. Surface roughnesses $\left(\mathrm{R}_{\mathrm{a}}\right.$, in $\left.\mathrm{nm}\right)$ of the archwires immersed in AS with $\mathrm{pH}$ values of 2.3, 3.3 and 4.3 for 1,7,14 and 30 days of immersion periods. The archwires had a length of $165 \mathrm{~mm}$ and weighed $0.10 \mathrm{~g}$.

\begin{tabular}{|c|c|c|c|c|c|}
\hline \multirow{2}{*}{\multicolumn{2}{|c|}{$\begin{array}{c}\text { As-is } \\
72.1 \pm 3.8\end{array}$}} & \multicolumn{4}{|c|}{ Immersion Period (days) } \\
\hline & & D1 & D7 & D14 & D30 \\
\hline \multirow{3}{*}{ 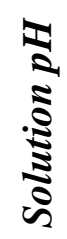 } & 2.3 & $78.2 \pm 3.86$ & $81.7 \pm 4.3$ & $50.6 \pm 4.8$ & $53.1 \pm 4.55$ \\
\hline & 3.3 & - & - & - & $51.3 \pm 5.62$ \\
\hline & 4.3 & - & - & - & $56.45 \pm 7.2$ \\
\hline
\end{tabular}


Table 4. The net ion release within each immersion interval and release rate of $\mathrm{Ni}$ and $\mathrm{Ti}$ which was obtained by normalizing the net ion release within each immersion interval by the number of the days in each interval.

\begin{tabular}{|c|cc|cc|}
\cline { 2 - 5 } \multicolumn{1}{c|}{} & \multicolumn{2}{c|}{ Ni } & \multicolumn{2}{c|}{ Ti } \\
\hline $\begin{array}{c}\text { Time Interval } \\
\text { (days) }\end{array}$ & $\begin{array}{c}\text { Net Ion Release } \\
\text { (ppb) }\end{array}$ & $\begin{array}{c}\text { Release Rate } \\
\text { (ppb/day) }\end{array}$ & $\begin{array}{c}\text { Net Ion Release } \\
(\mathbf{p p b})\end{array}$ & $\begin{array}{c}\text { Release Rate } \\
\text { (ppb/day) }\end{array}$ \\
$0-1$ & 1.601 & 1.601 & 2.251 & 3.634 \\
$1-7$ & 11.746 & 1.958 & 6.359 & 1.06 \\
$7-14$ & 2.715 & 0.388 & 2.251 & 0.322 \\
$14-30$ & 6.61 & 0.413 & 5.96 & 0.372 \\
\hline
\end{tabular}

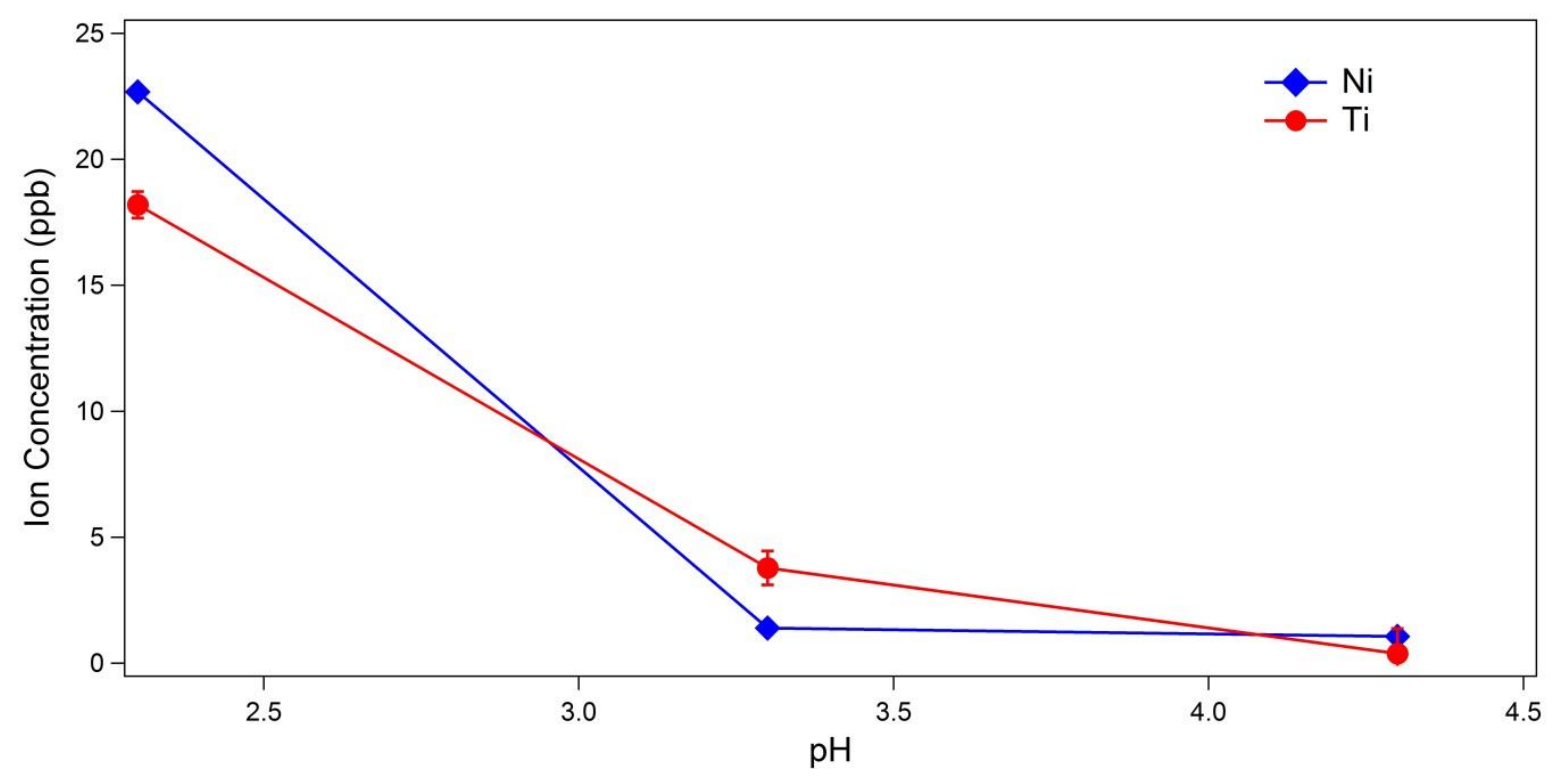

Figure 1. The concentration of released $\mathrm{Ni}$ and $\mathrm{Ti}$ ions in the AS solution with the $\mathrm{pH}$ values of 2.3, 3.3 and 4.3. It should be noted that error bars are present for each data point, however; they are not easily identified on the graph for measurements with very small error. 
a)

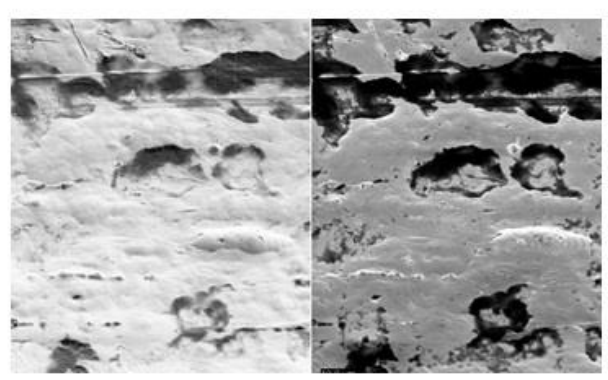

b)

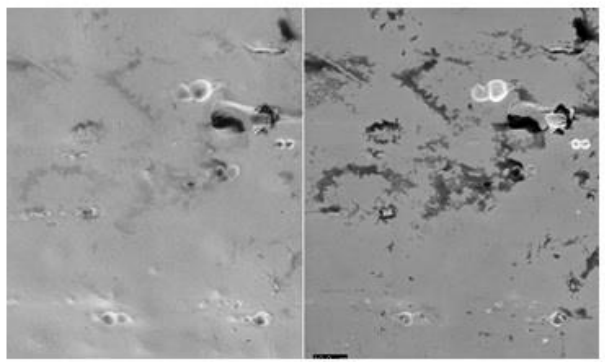

c)

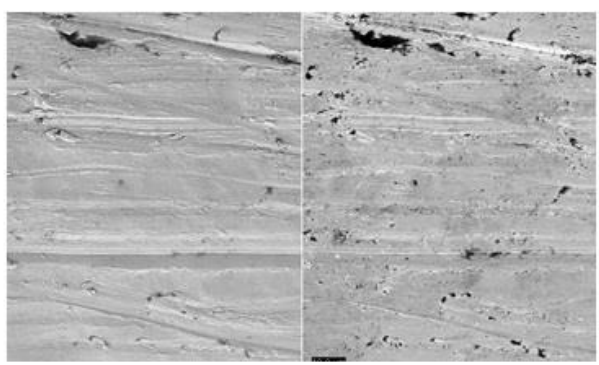

$-10 \mu \mathrm{m}$

Figure 2. SEM images obtained by inlens (the left frame) and SE detectors (the right frame) of the NiTi archwire surfaces immersed for 30 days in the AS with a pH value of (a) 2.3, (b) 3.3, and (c) 4.3. 


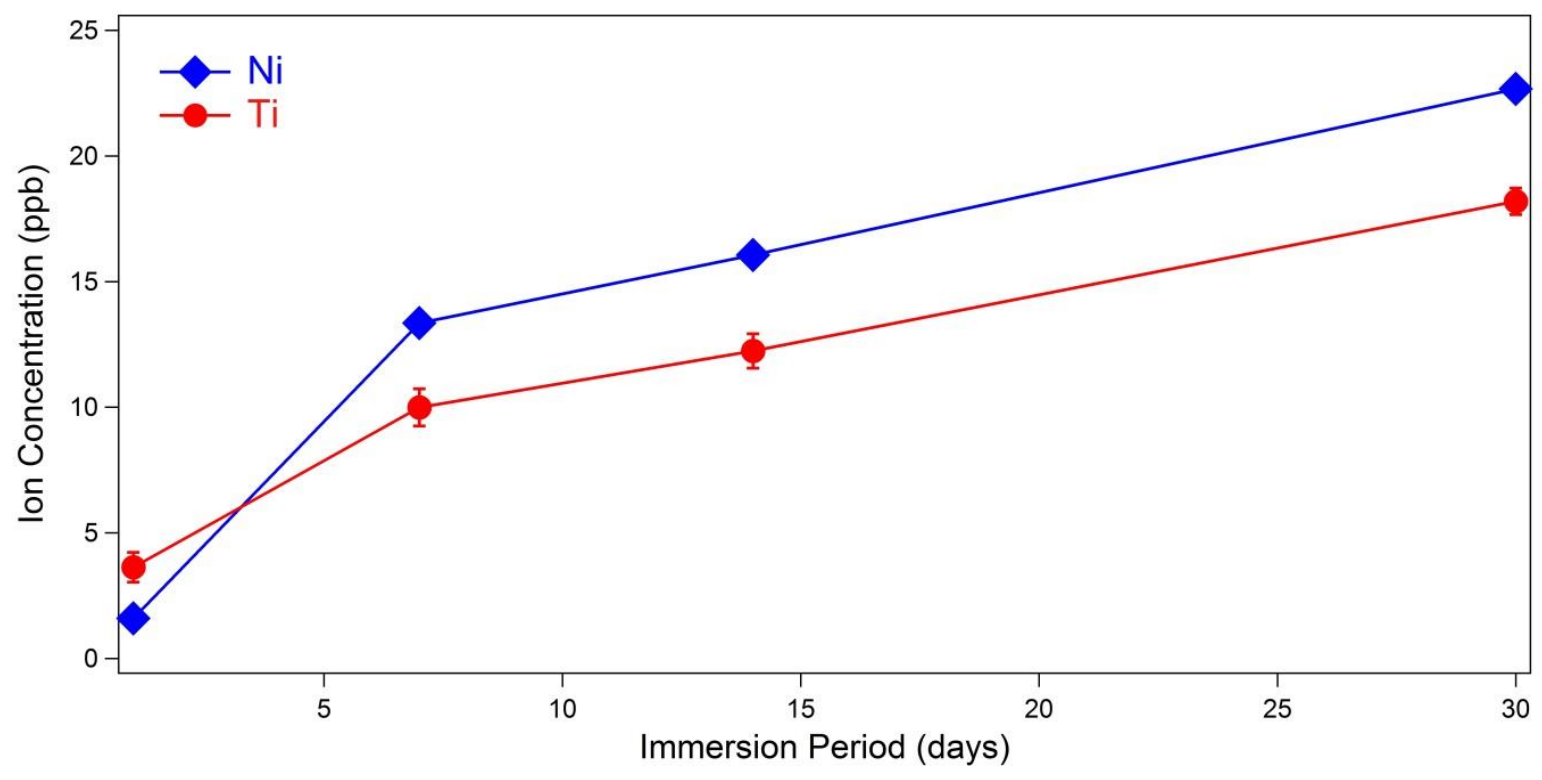

Figure 3. The cumulative concentration of released $\mathrm{Ni}$ and $\mathrm{Ti}$ ions in the AS solution with the $\mathrm{pH}$ value of 2.3 for $1,7,14$ and 30 days. It should be noted that error bars are present for each data point, however; they are not easily identified on the graph for measurements with very small error.

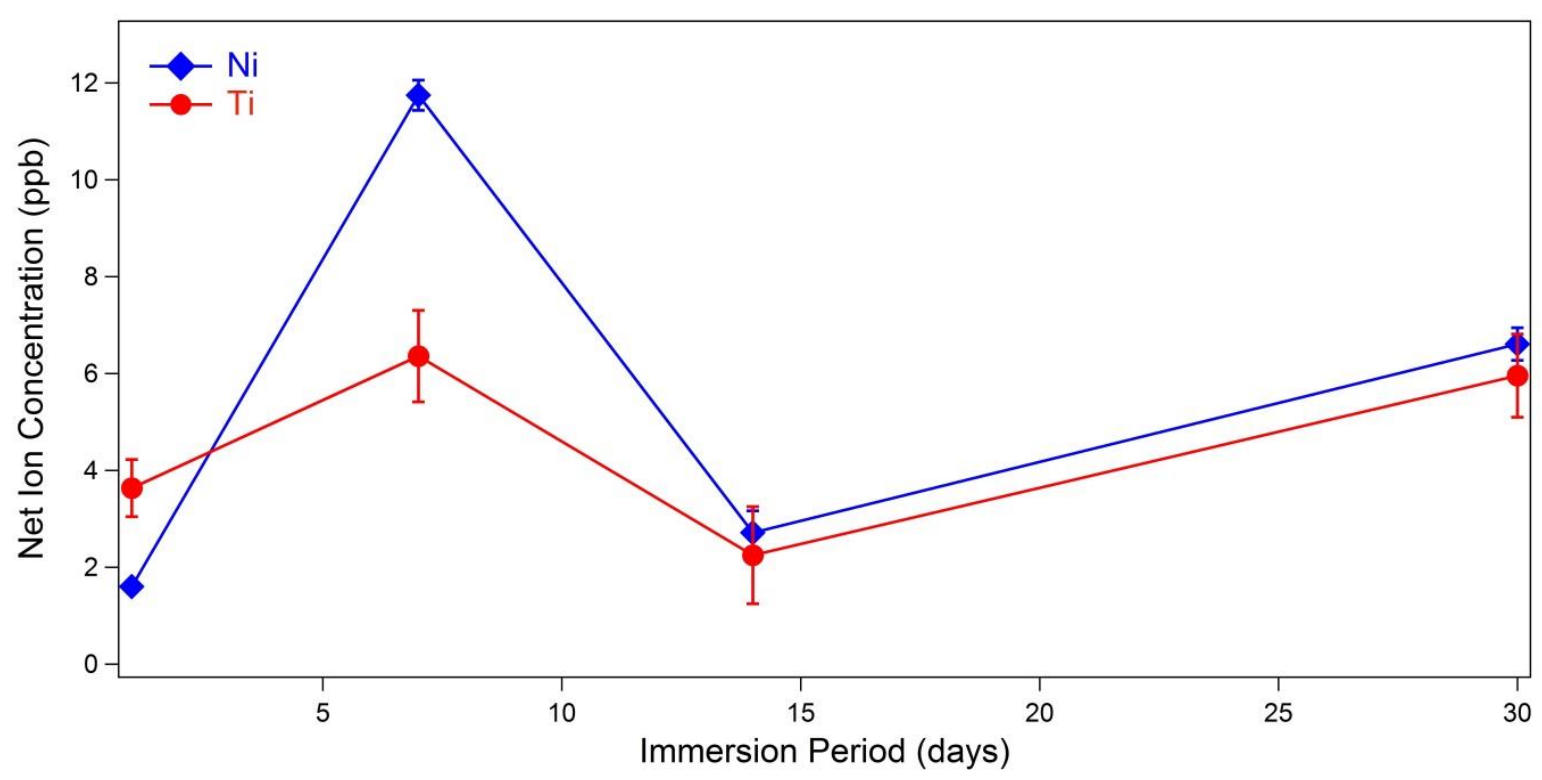

Figure 4. The concentration of net $\mathrm{Ni}$ and $\mathrm{Ti}$ ions in the AS solution with the $\mathrm{pH}$ value of 2.3 for 1, 7, 14 and 30 days. It should be noted that error bars are present for each data point, however; they are not easily identified on the graph for measurements with very small error. 


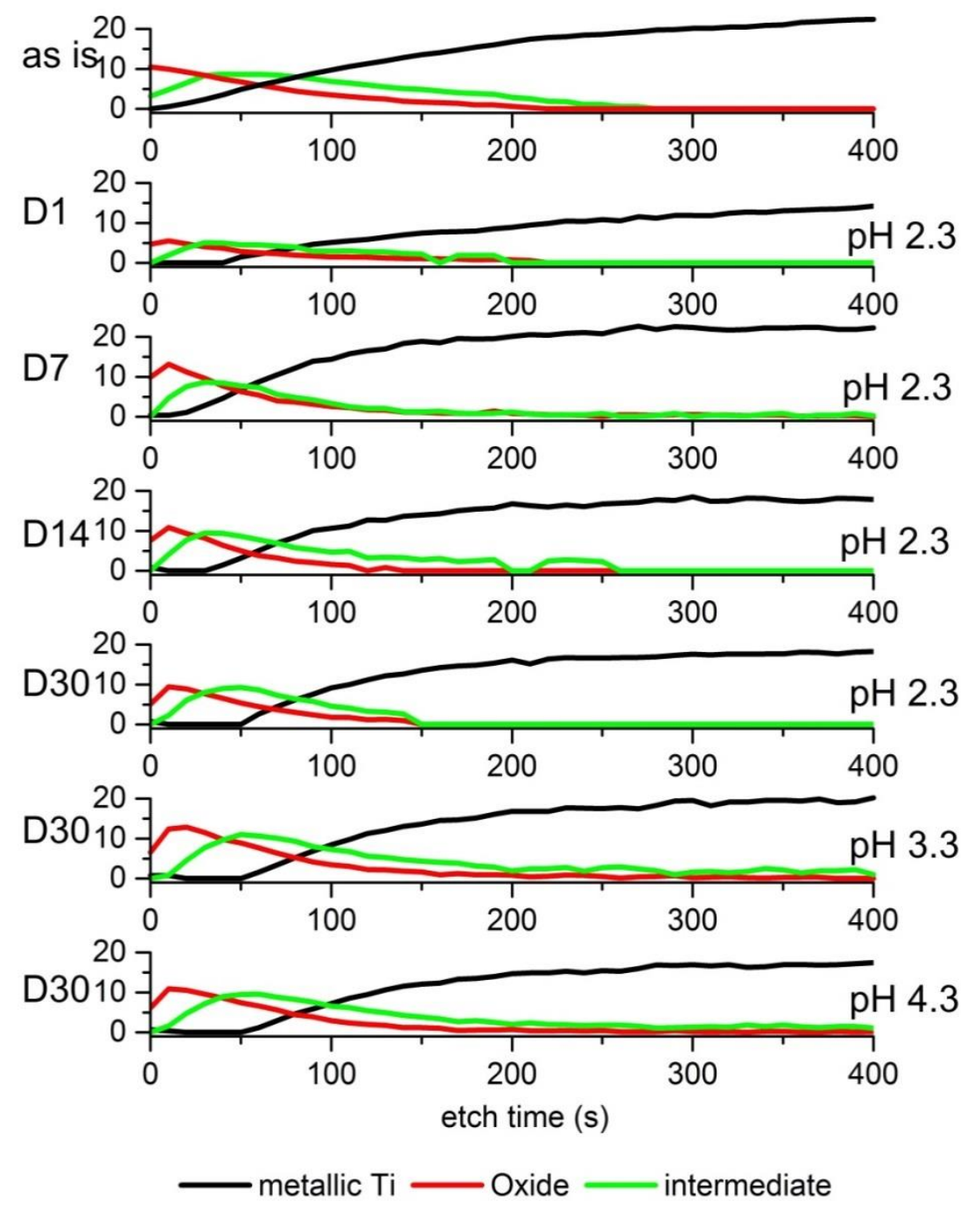

Figure 5. Depth profile data obtained by XPS. 

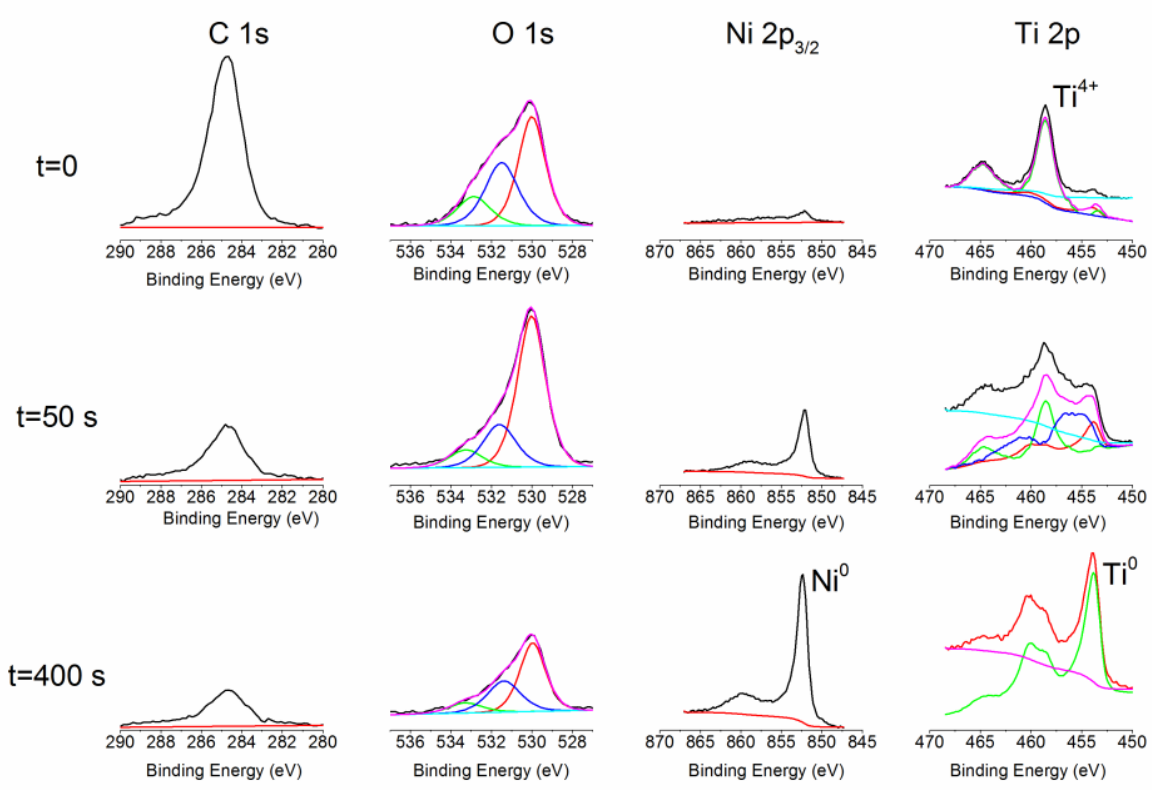

Figure 6. The XPS spectra recorded during the depth profiling of the archwire immersed in AS with a $\mathrm{pH}$ of 2.3 for 30 days.

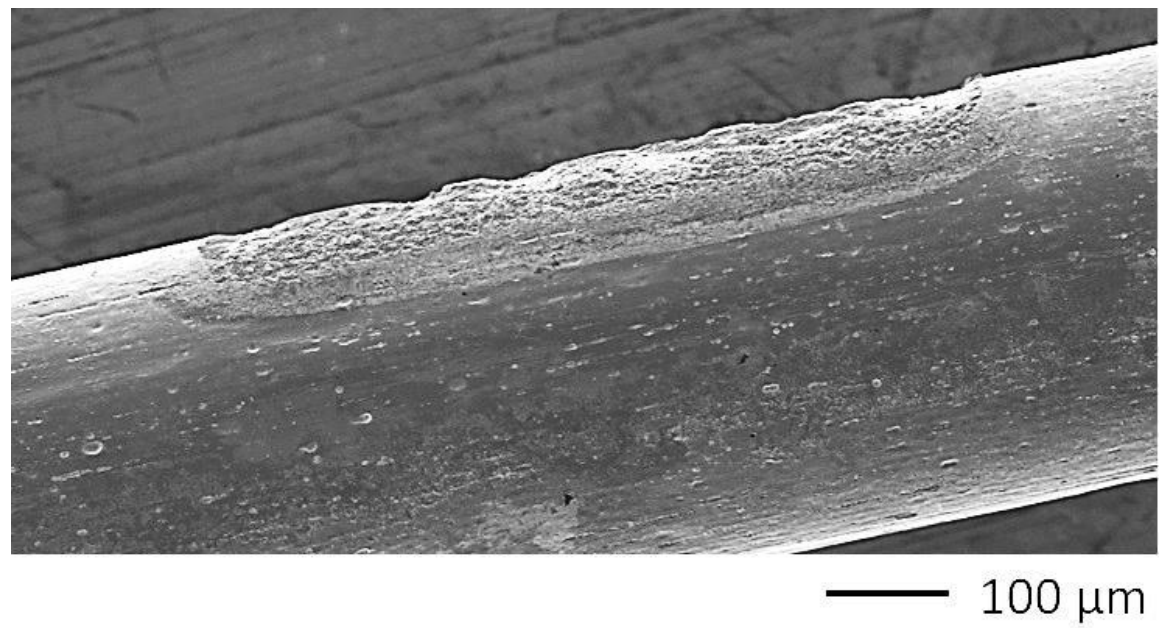

Figure 7. The deteriorated portion of surface on an as-is NiTi orthodontic archwire. 

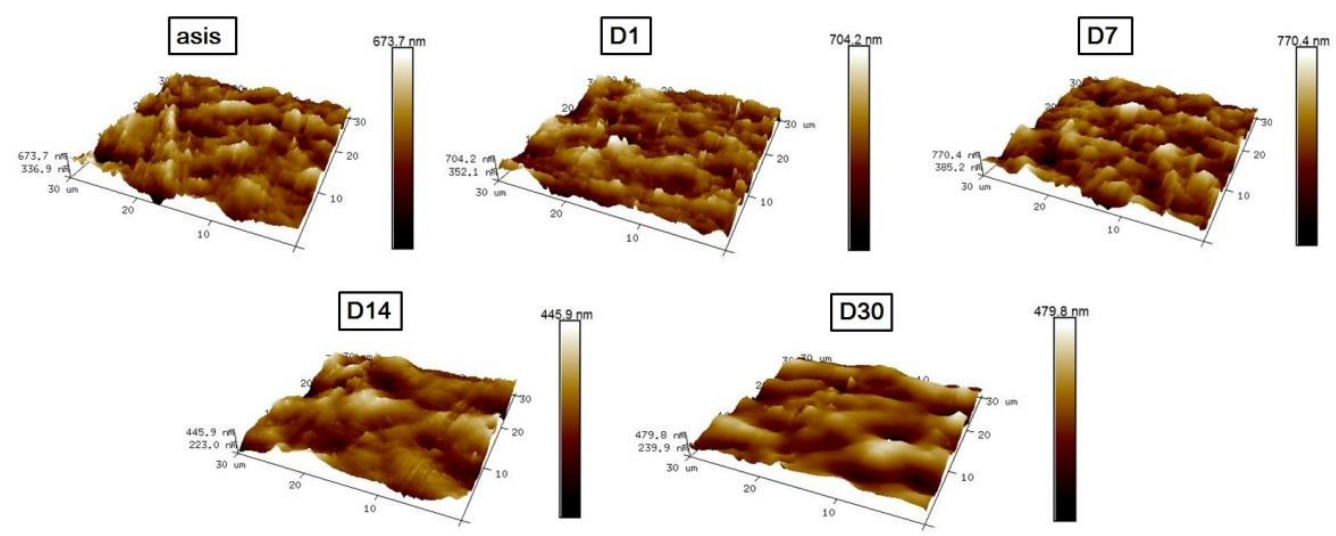

Figure 8. AFM images representing the surface topographies of the NiTi archwires immersed in the AS with $\mathrm{pH} 2.3$ for 1, 7, 14 and 30 days of immersion period (referred to as D1, D7, D14 and D30, respectively). An as-is archwire surface topography was also inserted in the figure for comparison purpose. 